\title{
A Novel Two-Step Technique for Retrieving Fractured Peripherally Inserted Central Catheter Segments Migrating into the Heart or the Pulmonary Artery
}

\author{
Juan Peng, Xiao-Ming Zhang, Lin Yang, Hao Xu, Nan-Dong Miao, \\ Yong-Jun Ren, Kang Liu, Xu-Li Min, Ke Yang, Shi Yang, and Cheng Yang
}

Sichuan Key Laboratory of Medical Imaging, Department of Radiology, Affiliated Hospital of North Sichuan Medical College, Nanchong, Sichuan 637000, China

Correspondence should be addressed to Lin Yang; linyangmd@163.com

Received 19 October 2015; Revised 14 November 2015; Accepted 13 July 2016

Academic Editor: Kenji Suzuki

Copyright (C) 2016 Juan Peng et al. This is an open access article distributed under the Creative Commons Attribution License, which permits unrestricted use, distribution, and reproduction in any medium, provided the original work is properly cited.

Objective. To report the experience of a percutaneous technique for retrieving fractured peripherally inserted central catheter (PICC) segments migrating into the heart or the pulmonary artery. Method. From April 2013 to July 2015, we performed percutaneous retrieval of fractured PICC segments migrating into the heart or the pulmonary artery in five cancer patients who had undergone chemotherapy via PICC. The fractures were diagnosed with chest plain radiography. The patients included three cases of breast cancer, one case of rectal cancer, and one case of lower limb Ewing's tumor. The fractures were retained in the vessels of the patients for 1 to 3 days. All the fractures were retrieved by using a novel two-step technique in the digital subtraction angiography (DSA) suite. This two-step technique involves inserting a pigtail catheter to the heart or the pulmonary artery to grasp the fractured catheter fragment and bring it to the lower segment of the inferior vena cava, followed by grasping and removing the catheter fragment with a retrieval loop system of the vena cava filter retrieval set. Result. The fractured PICC segments were removed successfully in all five patients via unilateral (four patients) or bilateral (one patient) femoral vein access. No complications occurred during the interventional procedure. Conclusion. Percutaneous retrieval can be a safe, convenient, and minimally invasive method for the removal of fractured PICC segments. The technique reported in this paper will be applicable for the retrieval of fractured PICC segments and other catheter fragments migrating into the heart or the pulmonary artery.

\section{Introduction}

Peripherally inserted central catheters (PICCs) are widely used to provide central venous access in chronically ill patients with long-term intravenous access requirements, such as those related to chemotherapy, parenteral alimentation, irritant drug infusion, and so forth. Multiple substantial complications of PICC, including catheter malposition, migration, obstruction, infection, thrombosis, and catheter fracture, have been reported in the literature [1-5]. Fractured catheter fragments should be retrieved to prevent further complications. Percutaneous retrieval of intravascular foreign bodies is considered the gold standard treatment because it is a minimally invasive, relatively simple, safe procedure, with low complication rates compared to conventional surgical treatment $[6,7]$. However, it can be difficult to retrieve the fractured catheter segments migrating into the heart or the pulmonary artery [8], so advanced techniques are required. In this report, we described our experience of 5 patients with fractured PICC segments in the heart or the pulmonary arteries which were successfully retrieved with a novel two-step method.

\section{Materials and Methods}

2.1. Patients. This is a retrospective report based on the medical records of 5 consecutive patients treated from April 2013 to July 2015. Of the 5 patients, 2 were males and 3 were females, with an average age of $39.4 \pm 17.2$ years (range: 10 to 55 years). The patients included three cases of breast 
TABLE 1: Summary of patient details.

\begin{tabular}{lcccc}
\hline Case number & Sex & Age & Diagnosis & Access \\
\hline 1 & Female & 44 years old & Breast cancer & Right femoral vein \\
2 & Female & 41 years old & Breast cancer & Right femoral vein \\
3 & Female & 47 years old & Breast cancer & Right femoral vein \\
4 & Male & 55 years old & Rectal cancer & Bilateral femoral vein \\
5 & Male & 10 years old & Lower limb Ewing's tumor & Right femoral vein \\
\hline
\end{tabular}

cancer, one case of rectal cancer, and one case of lower limb Ewing's tumor (Table 1). One patient presented cardiac symptoms (frequent ventricular premature beat), and the other four patients were asymptomatic with the fractured PICC segments. The fractured PICC segments were retained in the vessels of the patients for 1 to 3 days. The fracture was diagnosed with chest plain film.

2.2. Techniques. Through percutaneous right femoral venous access, the 11 Fr. coaxial retrieval sheath system of a vena cava filter retrieval set (William Cook Europe Aps, Sandet 6, DK4632, Bjaeverskov, Denmark) was advanced to the inferior vena cava over the wire guide (guide wire 0.035, $180 \mathrm{~cm}$; Terumo Corporation, 44-1, 2-Chome, Hatagaya, Shibuya-ku, Tokyo 151-0072, Japan), and then the inner coaxial catheter and wire guide were removed. The position of the coaxial retrieval sheath system was verified by injecting contrast medium. A 5 Fr. pigtail catheter (straight pigtail 0.038, $110 \mathrm{~cm}$; Terumo Corporation, 44-1, 2-Chome, Hatagaya, Shibuya-ku, Tokyo 151-0072, Japan) was placed at the fractured catheter body over the same wire guide. At the moment when the wire was removed, the fractured catheter body was grasped by the pigtail catheter. After the pigtail catheter and the fractured catheter coiled each other by rotating the pigtail catheter, the fractured catheter was brought to the lower segment of the inferior vena cava to be removed by pulling the pigtail catheter. After the pigtail catheter was removed, the retrieval loop system of the vena cava filter retrieval set was introduced through the coaxial retrieval sheath system to the inferior vena cava, until it was placed at the anterior end of the fractured catheter. At this moment, the fractured catheter was grasped by the device and taken to the sheath to be removed. A follow-up chest radiograph excluded residual fragments in the heart and the pulmonary artery, as well as the inferior vena cava. All the procedures should be performed under ECG guidance systematically.

\section{Result}

In this group of consecutive patients, the location of the fractured catheters was confirmed by an X-ray examination. The proximal and distal end of the fracture were located in the left and right branches of the pulmonary artery trunk, respectively, in two patients, and the proximal end was located in the superior vena cava and the distal end in the trunk of the pulmonary artery in two patients. The proximal end was located in the right atrium and the distal end in the right ventricle in one patient. All the fractured catheters were removed successfully without complications (Figure 1). In all the cases, the right femoral access was used in 4 cases, and both the right femoral access and the left femoral access were used in 1 case. The median of duration time of the procedure is $9 \mathrm{~min}$ with a range of 7 to $69 \mathrm{~min}$.

\section{Discussion}

If a catheter fracture occurs, the broken catheter will migrate distally along the blood stream and finally lodge in the superior vena cava, the right atrium, the right ventricle, the main pulmonary artery or its branches. Surov et al. [8] studied a total of 215 cases of intravenous catheter embolization. In their group, sites of catheter fragments were the superior vena cava or peripheral veins (15.4\%), the right atrium $(27.6 \%)$, right ventricle $(22.0 \%)$, and pulmonary arteries $(35.0 \%)$. The most common site for fragments was the pulmonary artery $(35.0 \%)$. In this group, the proximal end and the distal end of the fracture were located in the left and right branches of the pulmonary artery trunk, respectively, in two patients; the proximal end was located in the superior vena cava and the distal end in the trunk of the pulmonary artery in two patients; and the proximal end was located in the right atrium and the distal end in the right ventricle in one patient.

The majority of patients have no or modest symptoms but substantial sequelae may develop. The clinical presentation of catheter embolization varies considerably. A systematic review [8] reported that the clinical signs included catheter malfunction (56.3\%), arrhythmia (13.0\%), pulmonary symptoms $(4.7 \%)$, and septic syndromes (1.8\%). In this study, only 1 patient presented frequent ventricular premature beat, and the other 4 patients were asymptomatic. Intravascular foreign bodies should be removed to prevent potentially lethal complications. When there are symptoms or the risk of infection is high, the foreign body should be removed promptly. If the catheter adheres to the wall of the right heart system, leading to incessant arrhythmia, or the catheter goes through the unclosed foramen ovale into the left heart system, leading to serious artery embolism, it needs to be removed urgently. Usually, transient arrhythmia (premature beat and tachycardia) related to endocardiac catheter maneuvers may occur but disappears quickly after exiting the catheter.

Several percutaneous transcatheter retrieval techniques including a loop snare, a guide wire, a balloon, a forceps, and a basket catheter have been applied to remove cardiovascular catheter fragments and other foreign bodies [9-27]. The loop snare method is relatively safe with reliable effects, so it is currently widely used [9-11, 15-18]. However, when using a 


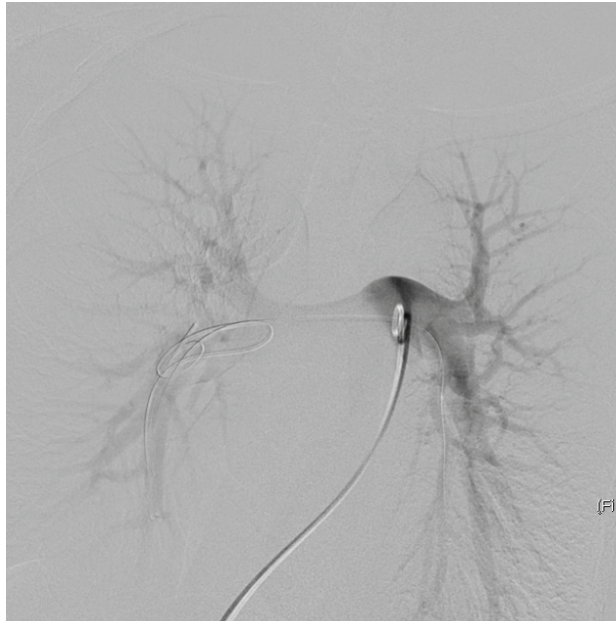

(a)

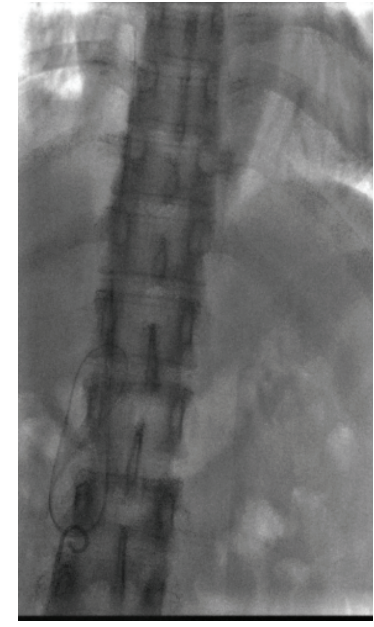

(b)

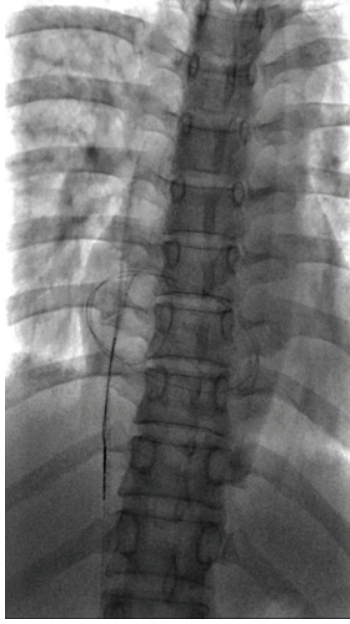

(c)

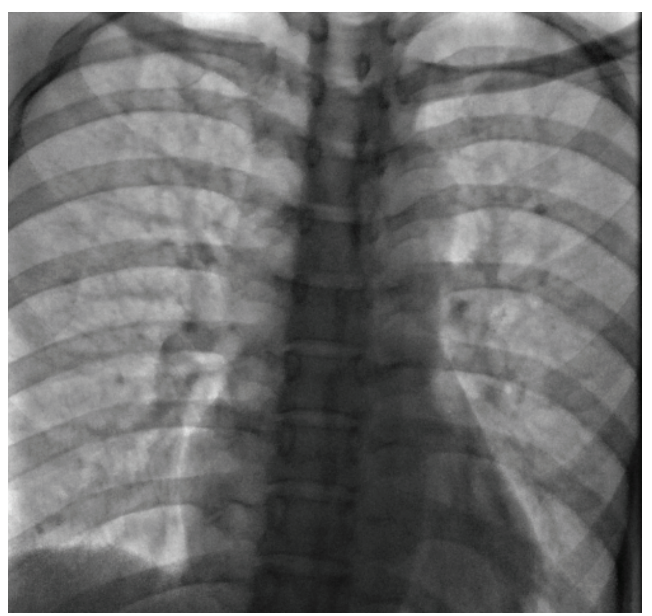

(d)

FiguRE 1: (a) The proximal and distal ends of the fractured catheter were located in the left and right branches of the pulmonary artery trunk, respectively, and the fractured catheter body was grasped by a pigtail catheter. (b) The fractured catheter was brought to the lower segment of the inferior vena cava to be removed. (c) The fractured catheter was grasped by the loop system of the vena cava filter retrieval set to be removed. (d) Chest radiograph after percutaneous retrieval of the fractured catheter, demonstrating the absence of any residual fragments.

loop snare to remove PICC fractures, the loop snare must be placed at the end of the catheter to grasp it. If the end of the catheter is lodged in the vessel wall or in a difficult plane, it will be difficult to grasp it successfully [19]. If the fractured catheter is located in the pulmonary artery, especially in the pulmonary artery branches, it will also be difficult to successfully grasp the end of the fractured catheter, because the movement of the loop cannot be easily controlled in the pulmonary artery and its branches. Teragawa et al. [9] reported a successful endovascular technique using a snare with a suture to retrieve a migrated broken PICC in the pulmonary artery of a chemotherapy patient. Although their technique is interesting and a useful method to control catheter movement, it may be associated with a risk of vascular injury and other unresolved problems, such as those relating to the thickness and type of suture used. Kawata et al. [10] experienced three cases of retrieval of silicone port catheters migrating into the cardiac ventricle or pulmonary artery. Several devices, including a snare wire, an ablation catheter, and a basket catheter, in combination with an interventional guiding catheter were applied to retrieve them. Yen et al. [11] reported 13 patients who had an embolization caused by central venous catheter fragments including 4 PICCs, and they utilized the "goose-neck" snare to retrieve a catheter fragment with its free end floating in the pulmonary trunk. If the fractured catheter fragment was engaged in the trabecula of the right ventricle and could not be grasped by the loop snare, a floppy guide wire was inserted through the other vein to cross the fragment and grasp its tip using the loop snare. As discussed previously, a guide wire can be used with a catheter to construct a homemade loop snare. The technique of the balloon is useful in the recovery of stents; it requires a guide wire passing through the intravascular foreign body (IFB) or a portion of it. It is important to choose an appropriate retrieval balloon. If the balloon is too large, it will not pass the IFB; if the balloon is too small, it will not 
capture the IFB $[22,28]$. The grasping power of the forceps is advantageous in removing a foreign body strongly adhering to the vessel wall; however, in this case, to control the catheter head is difficult. The catheter material is stiff, and there is a danger of causing damage to vessels [22, 28, 29]. The basket is a well-known device that is often used in the biliary system. This catheter is capable of withdrawing relatively large foreign bodies and is preferred in situations where a foreign body is attached to the vessel wall without a free edge [29]. As it is made of stiff material with less flexibility, it can sometimes damage the vessel wall $[22,28,29]$. Another disadvantage of basket is its poor navigation capability [28].

In the present study, the fractured PICC segments located in the heart or the pulmonary artery were removed successfully using a pigtail catheter in combination with a vena cava filter retrieval set. However, there is a drawback of losing the retrieved catheter during the moment in between the two steps. If the fractured catheter fragment returns to the heart from the inferior vena cava, a pigtail catheter is inserted through the other femoral vein to bring the fractured catheter fragment to the lower segment of the inferior vena cava, and then it can be grasped and removed by the retrieval loop through the coaxial retrieval sheath system successfully. These procedures will increase the duration of the procedure. In this study, both the right femoral access and the left femoral access were used in 1 case; the duration of the procedure is $69 \mathrm{~min}$.

Our experience is that the fractured catheter bodies in the heart or the pulmonary artery can be easily grasped using a pigtail catheter, and when the fractured catheters are brought to the inferior vena cava, they can also be easily grasped and removed using a vena cava filter retrieval set.

In conclusion, a two-step method of retrieving fractured PICC segments migrating into the heart or the pulmonary artery is described in this study. It adds a valuable technical option to the existing percutaneous techniques for retrieving cardiovascular foreign bodies.

\section{Competing Interests}

The authors declare that they have no competing interests.

\section{References}

[1] V. Chopra, S. Anand, S. L. Krein, C. Chenoweth, and S. Saint, "Bloodstream infection, venous thrombosis, and peripherally inserted central catheters: reappraising the evidence," American Journal of Medicine, vol. 125, no. 8, pp. 733-741, 2012.

[2] S. S. Amerasekera, C. M. Jones, R. Patel, and M. J. Cleasby, "Imaging of the complications of peripherally inserted central venous catheters," Clinical Radiology, vol. 64, no. 8, pp. 832-840, 2009.

[3] C. Dupont, H. Gouya, R. Panzo et al., "Complications of peripherally inserted central catheters in adults with cystic fibrosis or bronchiectasis," Journal of Vascular Access, vol. 16, no. 3, pp. 245-249, 2015.

[4] P. J. Carr and J. C. Rippey, "Upper extremity deep vein thrombosis: a complication of an indwelling peripherally inserted central venous catheter," Clinical Case Reports, vol. 3, no. 3, pp. 170-174, 2015.

[5] P. Cotogni, C. Barbero, C. Garrino et al., "Peripherally inserted central catheters in non-hospitalized cancer patients: 5-year results of a prospective study," Supportive Care in Cancer, vol. 23, no. 2, pp. 403-409, 2014.

[6] J. M. Motta Leal Filho, F. C. Carnevale, F. Nasser et al., "Endovascular techniques and procedures, methods for removal of intravascular foreign bodies," A Revista Brasileira de Cirurgia Cardiovascular, vol. 25, no. 2, pp. 202-208, 2010.

[7] R. Sheth, V. Someshwar, and G. Warawdekar, "Percutaneous retrieval of misplaced intravascular foreign objects with the Dormia basket: an effective solution," CardioVascular and Interventional Radiology, vol. 30, no. 1, pp. 48-53, 2007.

[8] A. Surov, A. Wienke, J. M. Carter et al., "Intravascular embolization of venous catheter causes, clinical signs, and management: a systematic review," Journal of Parenteral and Enteral Nutrition, vol. 33, no. 6, pp. 677-685, 2009.

[9] H. Teragawa, T. Sueda, Y. Fujii et al., "Endovascular technique using a snare and suture for retrieving a migrated peripherally inserted central catheter in the left pulmonary artery," World Journal of Cardiology, vol. 5, no. 9, pp. 369-372, 2013.

[10] M. Kawata, K. Ozawa, T. Matsuura et al., "Percutaneous interventional techniques to remove embolized silicone port catheters from heart and great vessels," Cardiovascular Intervention and Therapeutics, vol. 27, no. 3, pp. 196-200, 2012.

[11] H.-J. Yen, B. Hwang, P.-C. Lee, and C. C. Meng, "Transcatheter retrieval of different types of central venous catheter fragment: experience in 13 cases," Angiology, vol. 57, no. 3, pp. 347-353, 2006.

[12] M. Ootaki, S. Kuribayashi, and S. Matsuyama, "Percutaneous retrieval of intravascular foreign body from the pulmonary artery," Nippon Igaku Hoshasen Gakkai Zasshi. Nippon Acta Radiologica, vol. 53, no. 12, pp. 1374-1379, 1993.

[13] F.-S. Yang, I. Ohta, H.-J. Chiang, J. C.-T. Lin, S.-L. Shih, and Y.C. Ma, "Non-surgical retrieval of intravascular foreign body: experience of 12 cases," European Journal of Radiology, vol. 18, no. 1, pp. 1-5, 1994.

[14] O. K. Kim, S. H. Kim, J. B. Kim et al., "Transluminal removal of a fractured and embolized indwelling central venous catheter in the pulmonary artery," Korean Journal of Internal Medicine, vol. 21, no. 3, pp. 187-190, 2006.

[15] S. Cekirge, J. P. Weiss, R. G. Foster, H. L. Neiman, and G. K. McLean, "Percutaneous retrieval of foreign bodies: experience with the nitinol Goose Neck snare," Journal of Vascular and Interventional Radiology, vol. 4, no. 6, pp. 805-810, 1993.

[16] J.-H. Jang, S.-I. Woo, D.-H. Yang, S.-D. Park, D.-H. Kim, and S.H. Shin, "Successful coronary stent retrieval from the ascending aorta using a gooseneck snare kit," Korean Journal of Internal Medicine, vol. 28, no. 4, pp. 481-485, 2013.

[17] M. Ghaderian, M. R. Sabri, and A. R. Ahmadi, "Percutaneous retrieval of an intracardiac central venous port fragment using snare with triple loops," Journal of Research in Medical Sciences, vol. 20, no. 1, pp. 97-99, 2015.

[18] M. Bostan, M. Durakoğlugil, Ö. Satiroğlu, B. Erdivanli, and G. Tufan, "Retrieval of embolized tip of port catheter from branch of right pulmonary artery using a macro snare catheter," Interventional Medicine and Applied Science, vol. 6, no. 2, pp. 93-95, 2014.

[19] A. K. Gupta, S. Purkayastha, and T. Krishnamoorthy, "Percutaneous retrieval of intravascular broken catheter fragments. A 
novel technique using a balloon," Interventional Neuroradiology, vol. 11, no. 2, pp. 149-154, 2005.

[20] A. A. Schricker, G. K. Feld, and S. Tsimikas, "Retrieval of a detached transseptal sheath tip from a right pulmonary artery branch following catheter ablation," Catheterization and Cardiovascular Interventions, vol. 86, no. 6, pp. 1131-1135, 2015.

[21] A. B. Ramondo, L. Favero, and R. Chioin, "Percutaneous retrieval of a broken catheter from the left atrium in an adult," Journal of Interventional Cardiology, vol. 15, no. 5, pp. 417-419, 2002.

[22] J. B. Woodhouse and R. Uberoi, "Techniques for intravascular foreign body retrieval," Cardio Vascular and Interventional Radiology, vol. 36, no. 4, pp. 888-897, 2013.

[23] H. Zamani, K. Babazadeh, R. Ghaffari, H. Karami, S. Fattahi, and F. M. Esbuie, "The successful withdrawal of a migrated central venous catheter," Caspian Journal of Internal Medicine, vol. 3, no. 4, pp. 550-553, 2012.

[24] M. Funami, T. Kashima, M. Aiba et al., “Technic of nonsurgical removal of iatrogenic catheter fragment from the heart with a modified basket grasping forceps," Kyobu Geka, vol. 41, no. 7, pp. 566-567, 1988.

[25] P.-C. Wang, H.-L. Liang, T.-H. Wu et al., "Percutaneous retrieval of dislodged central venous port catheter: experience of 25 patients in a single institute," Acta Radiologica, vol. 50, no. 1, pp. 15-20, 2009.

[26] J. B. Selby, C. J. Tegtmeyer, and G. M. Bittner, "Experience with new retrieval forceps for foreign body removal in the vascular, urinary, and biliary systems," Radiology, vol. 176, no. 2, pp. 535538, 1990.

[27] T. K. Egglin, K. W. Dickey, M. Rosenblatt, and J. S. Pollak, "Retrieval of intravascular foreign bodies: experience in 32 cases," American Journal of Roentgenology, vol. 164, no. 5, pp. 1259-1264, 1995.

[28] C. Floridi, L. Nocchi-Cardim, M. De Chiara, A. M. Ierardi, and G. Carrafiello, "Intravascular foreign bodies: what the radiologist needs to know," Seminars in Ultrasound, CT and MRI, vol. 36, no. 1, pp. 73-79, 2015.

[29] M. Tateishi and Y. Tomizawa, "Intravascular foreign bodies: danger of unretrieved fragmented medical devices," Journal of Artificial Organs, vol. 12, no. 2, pp. 80-89, 2009. 


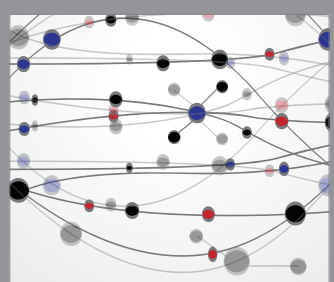

The Scientific World Journal
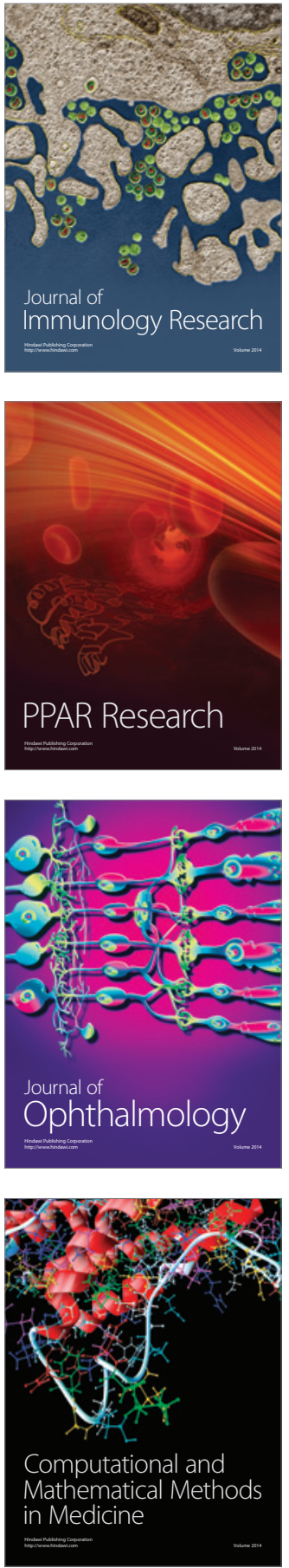

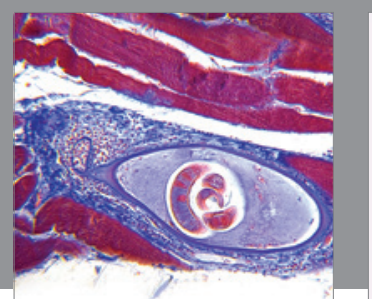

Gastroenterology Research and Practice

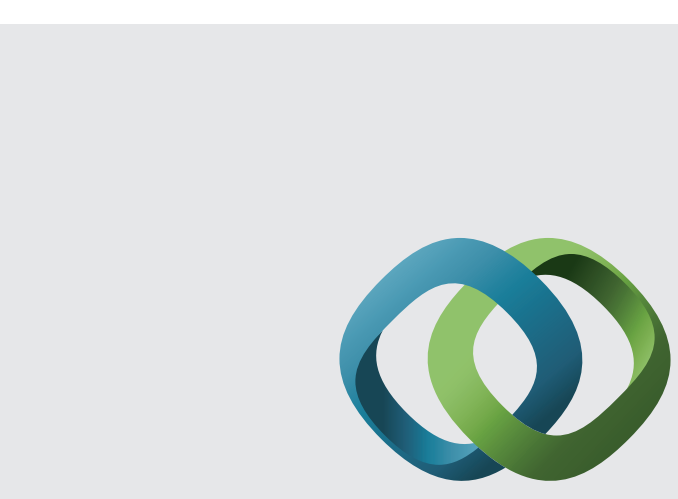

\section{Hindawi}

Submit your manuscripts at

http://www.hindawi.com
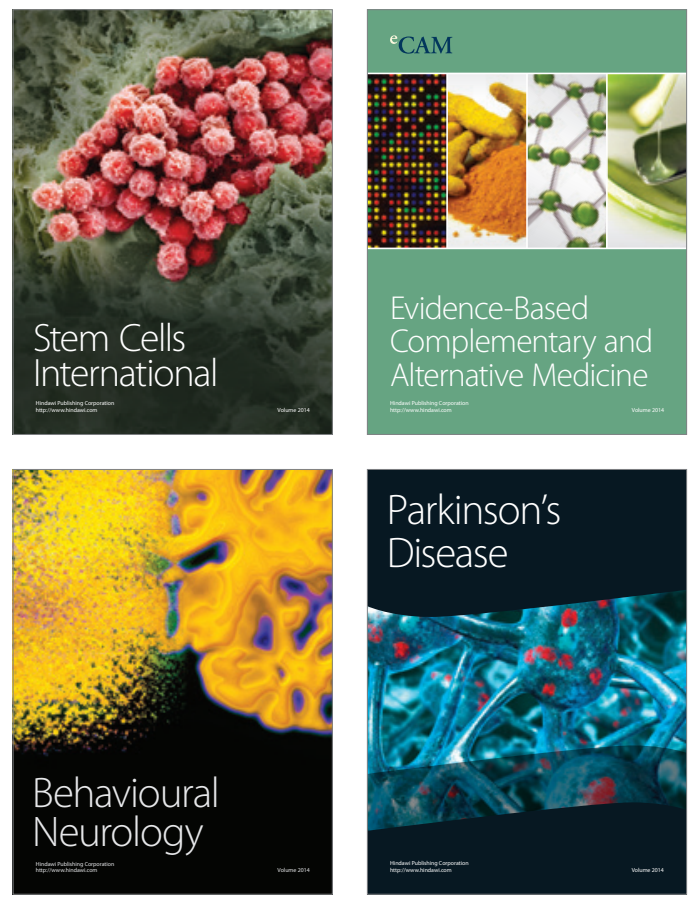
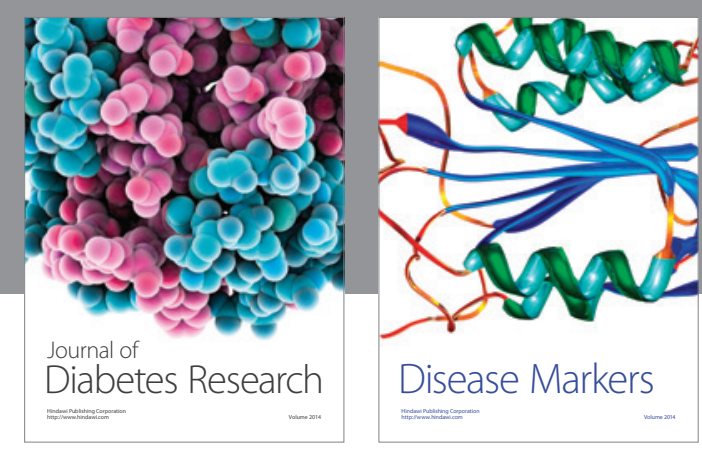

Disease Markers
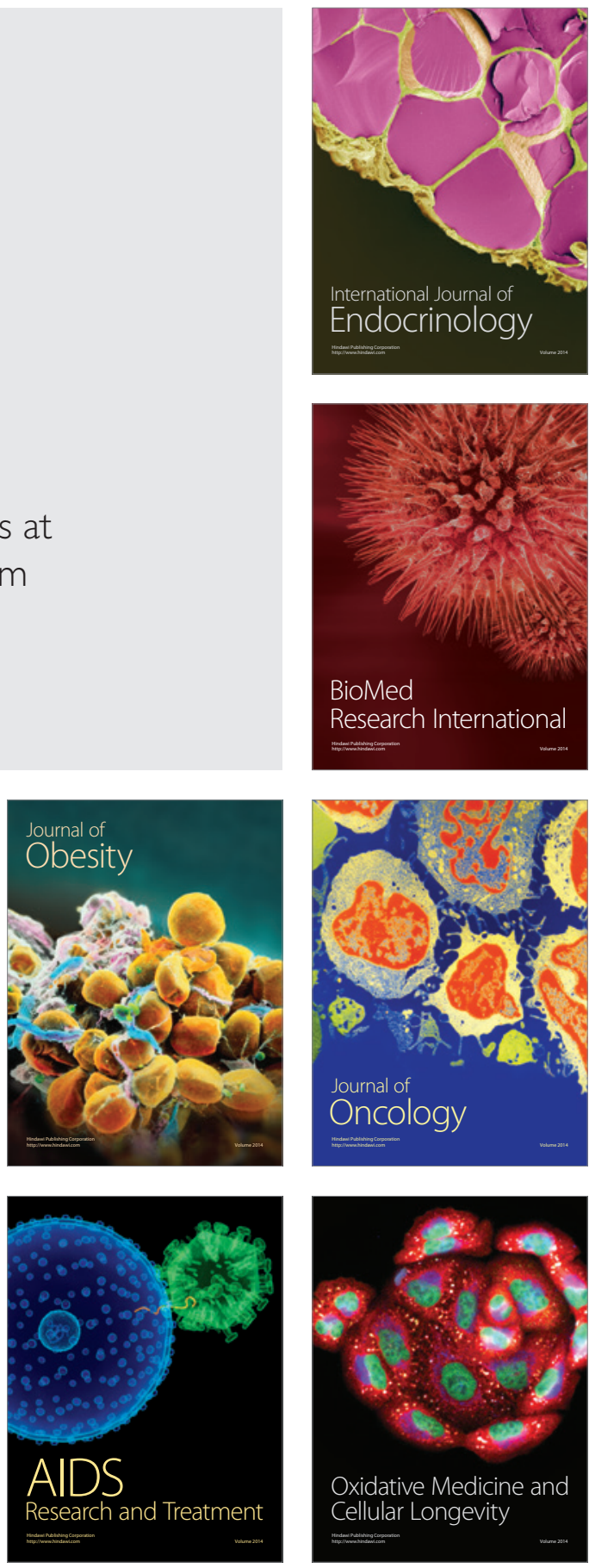